\title{
Research on the Characteristic Construction of the Blue Oceanic General Education Curriculum
}

\author{
Chunyan Tian \\ Dalian Ocean University \\ Dalian, Liaoning, China 116023
}

\begin{abstract}
On the basis of the construction of blue oceanic general education curriculum of the Dalian Ocean University, this paper has analyzed and defined the connotation of oceanic general education and actively explored the effective ways to construct the blue oceanic general education curriculum through referring to the development experience of general education curriculum of universities in our country especially the ocean universities. It improves the construction level of oceanic general education curriculum and the quality of talent training, promotes the connotative development of universities and offers useful reference for the characteristic development of oceanic general education curriculum of other local colleges.
\end{abstract}

Keywords—oceanic general education; curriculum; university

\section{INTRODUCTION}

The oceanic education in broad sense includes all activities that enhances people's knowledge about ocean culture and marine consciousness and improves their ocean behavior. The oceanic education in narrow sense refers to the activities that educators train the educatee with purpose, plan and organization about the oceanic natural characteristic and understanding of social value, oceanic professional ability and the oceanic literacy formed by people's quality elements like the marine consciousness of knowledge, ocean morality and ocean behavior. The oceanic education appearing in this paper is in the narrow sense.

\section{CONNOTATION OF THE OCEANIC GENERAL EDUCATION}

The "oceanic general education" doesn't have a standard definition in domestic educational circles and practical departments. The literal meaning refers to the specific oceanic general education of the marine specialty and professional fields related to the ocean, as well as the general education on oceanic topics. In the Exploration on Problems in the Oceanic General Education, the scholar Yang Haiping addresses the oceanic general education corresponding to the above two concepts now has about two modes. One is the oceanic general education with characteristics of marine or aquaculture specialty, like the general education curriculum in Ocean University of China. In 2010, it centered on the development planning of "the 12th Five-year Plan" and the new round of undergraduate talent training program and redefined five knowledge areas of general education in schools, namely "marine environment and ecological civilization", "scientific spirit and scientific technology", "social development and citizen education" and "humanities classics and humanistic culture" as well as "artistic appreciation and aesthetical life", highlighting the school-running characteristics in ocean and aquaculture. Another is the general education on oceanic topics, namely the knowledge of oceanic topic in the general education. The oceanic general curriculum in Dalian Ocean University has the characteristics of marine or aquaculture specialty. The curriculums provided have covered the aspects like marine organism, marine geology, marine environment, marine humanity and marine economy, marine industry, marine strategy as well as the marine politics and law.

\section{THE OCEANIC GENERAL EdUCATION CURRICULUM BELONGS TO THE “LIGHT BLUE” LEVEL IN THE BLUE CURRICULUM SYSTEM}

In years of school-running practice, the Dalian Ocean University has gradually formed its own characteristics and the school-running concept of "Blue University", in order to achieve the grand objective of building the high level ocean university through constructing the blue subject system and teaching staff, implementing the training plan of blue talents, creating the innovative platform of blue science and technology, inheriting and renovating the blue culture as well as constructing the high grade blue campus. The important content of implementing the training plan of blue talents is the blue curriculum system designed in accordance with the principle of layer-by-layer in-depth promotion. With the general education curriculum, the basic courses in discipline, the specialized courses and the concentrated practical teaching as the carriers, four levels of the blue curriculum system namely the "light blue to sky blue to azure blue and to dark blue" has been constructed in sequence. Strengthening the construction of blue curriculum system is an important guarantee to build the blue university and train high quality marine talents with blue and open consciousness of marine protection and sustainable development. With respect to the general education, as the public elective course, the blue oceanic curriculums provided in the school embody the oceanic features and the blue culture, belonging to the "light blue" level in the blue curriculum system. 


\section{WAYs TO CONSTRUCT THE BLUE OCEANIC GENERAL EDUCATION CURRICULUM}

\section{A. Aim at Training Students' Marine Consciousness and Build the Blue Oceanic General Education Curriculum Group}

The main purpose of strengthening the construction of blue oceanic general education curriculum is to train students' marine consciousness, establish the modern concept of ocean and provide a powerful ideological guarantee to construct the great power of ocean. The marine consciousness includes the consciousnesses of ocean strategy, marine territory, maritime sovereignty, marine resource, marine safety and marine channel as well as marine ecology.

The school aims at training students' marine consciousness and improves the proportion of the blue oceanic general education curriculum in the general education system and builds the blue oceanic general education curriculum group to let the marine consciousness "walk into" the classroom. The blue oceanic general education curriculum group should include the curriculums of Introduction to the Sea Power, Introduction to Ocean Management, Outline of the China Sea Rights, Introduction to Marine Resource, Outline of China Nautical History, Introduction to the Marine Environment, Introduction to Marine Development and Protection, Introduction to Ocean Science, Marine Ecology, General Theory of Aquaculture and Introduction to Ocean Culture. The teaching contents are organized through eight modules including marine science, marine technology, marine resource, marine environment, marine humanity, marine economy, marine strategy and marine politics and law (as shown in the "Fig. 1"), to build the blue oceanic general education curriculum suitable for all the students to study, so that the arts students can learn the marine science, marine resource and marine environment and the science students can clearly know about the marine economy, marine strategy and marine politics and law. It helps students to fully realize the importance of ocean, improve their marine consciousness, consciousness of ecological civilization and sustainable development.

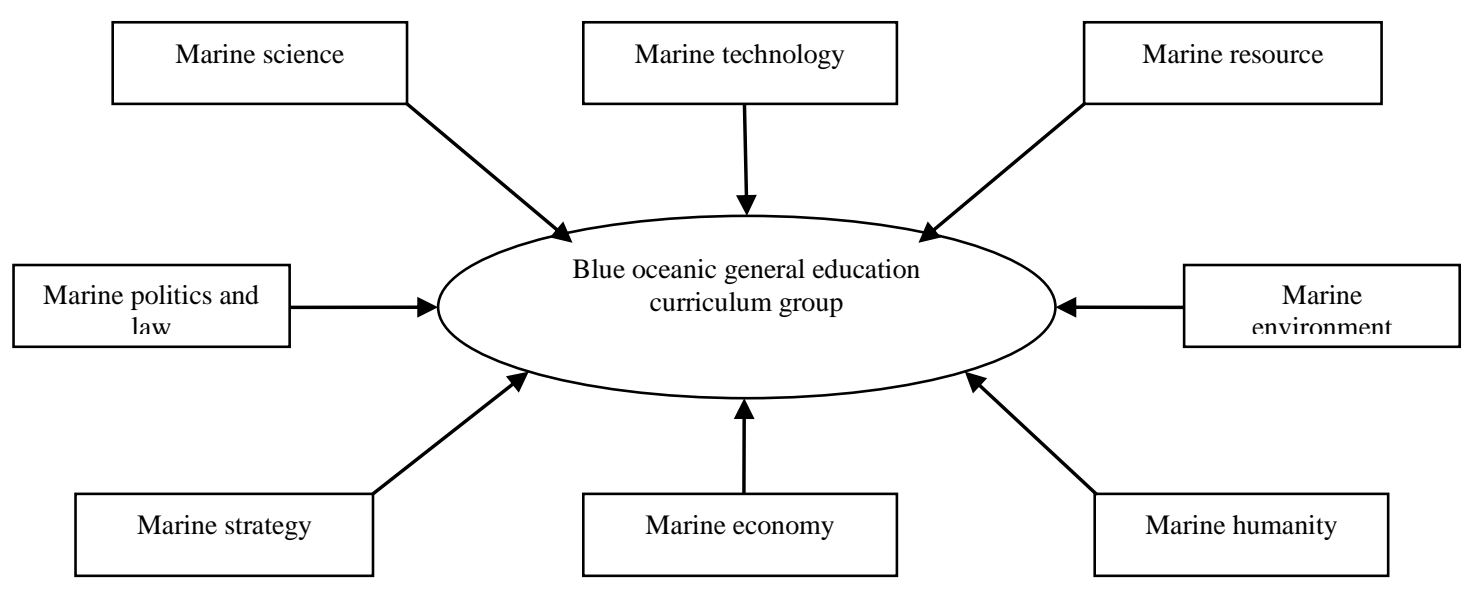

Fig. 1. Blue oceanic general education curriculum group

\section{B. Revise the Talent Training Program and Integrate the Teaching Contents of Blue Oceanic General Education Curriculum}

Since November 2015, the school has launched the formulation of 2016 edition training program for undergraduate talents, centered on the overall objective of talent training and further improved the general curriculum, basic courses in discipline, specialized course and practical teaching as well as the scientific and reasonable blue curriculum system. In the new edition training program, the public elective courses can be divided into five types: the natural sciences, the humanities and social sciences, the artistic sports, the blue ocean and the innovation and entrepreneurship. Teachers are encouraged to provide the characteristic blue oceanic general curriculums concerning marine nature, marine culture, marine economy and marine politics helpful to improve students' consciousness of marine nature, marine culture, marine economy and marine politics. Courses like the Marine Economy Evaluation Model and Method, the Game between Marine Microorganism and Human Being, the Marine Economy and Security, the Price Evaluation of Marine Resource Asset are added to further meet students' requirements of individualized learning. The school integrates the teaching contents of blue oceanic general education curriculum according to the revision status of the new edition training program. Meanwhile, the syllabus of public elective course in the 2016 edition undergraduate talent training program is revised again. The newly revised syllabus of the blue oceanic general education curriculum becomes an important basis in curriculum construction and execution.

\section{Strengthen the Teaching Mode Reform and Enrich the Teaching Methods and Ways of the Blue Oceanic General Curriculums}

It is necessary to pursue the diversification of teaching forms in the blue oceanic general education curriculum, carry out multiform teaching demonstration activities as the extension of classroom teaching and renovate ways and means 
of the blue oceanic general education. For example, make the best of the existing audio-visual teaching materials, like "Move towards the Ocean" to watch and discuss with students; make the most of network resources to let students acquire the knowledge about ocean independently; make the best of marine resources in Dalian, Liaoning, taking the marine museum, museum, science and technology museum and marine scientific research institutions as the practice bases of the blue oceanic general education curriculum to teaching college students; establish the corresponding research groups according to students' interests and strong points, like the marine science and technology group, marine environmental protection group and the marine laws and regulations group and integrate with activities in the school like the marine culture exhibition, the academic lecture of oceanic topic and marine knowledge contest, in order to fully stimulate students' enthusiasm and ensure the continuous improvement of the curriculum teaching quality.

\section{Promote the Construction of Blue Oceanic Teaching Materials and Compile the High Level Blue Oceanic General Education Teaching Materials}

Teaching materials are the most direct and effective carrier of education. The construction of oceanic general teaching materials should be strengthened to vigorously develop the blue oceanic general education. Our country has fewer oceanic general teaching materials than that of the developed countries. Besides, the existing teaching materials for marine specialty are not suitable for the oceanic general education. Therefore, it is an effective way to promote the oceanic general education through compiling the teaching materials of oceanic general education on the basis of curriculum construction. The textbook compilation should adhere to the following three principles: A. use simple knowledge point, concise language and rich diagram to stimulate students' thirst for knowledge of ocean knowledge; B. highlight the practical principle, greatly increase the contents of marine practical education, to benefit students' daily life; C. use diversified structural system to meet students' learn demands. In November 2014, the blue textbook construction committee was established in the school to promote the blue oceanic textbook construction and compile high level blue oceanic general education textbooks.

\section{E. Promote the Construction of Course to Share the Excellent Resources in the Blue Oceanic General Education Curriculums}

Seize the opportunity of "Curriculum Construction Year", formulate the Implementation Plan to Further Strengthen the Curriculum Construction of Dalian Ocean University and construct the curriculum group, the platform course, the sharing course of excellent resource and the micro course project including the oceanic general education course. The curriculum resource system should enrich and suit the network communication. The school has set up the project to support the construction of more than twenty blue oceanic general education curriculums, sharing courses of excellent resources and micro courses, so as to promote the construction of teaching resource sharing system of the blue oceanic general education curriculum and promote the transformation of teaching concept and the reform of teaching contents and methods. In 2015, three courses of our school like the National Sea Power in Historical View and the Aquaculture Water Environmental Chemistry acquired the provincial sharing course of excellent resources, expanding the scope of webbased teaching platform of the oceanic general education curriculum in our school.

\section{F. Rely on the Marine Course Union in Ocean Universities to Promote the Innovation of Oceanic Teaching Pattern}

In November 2015, the Fifth National Conference on Educational Union of Ocean Universities was held in our school. The teaching reform and development was discussed by staff in the dean's office of more than thirty national ocean universities, involving the curriculum construction and reform. We interview related personnel in the dean's offices of the Ocean University of China, the Shanghai Ocean University and the Dalian Maritime University and refer to the methods and experience of them in the oceanic general education curriculum construction. After the conference, according to the present construction level and distribution of domestic universities, the Ocean University of China and the Dalian Ocean University launched to establish the Oceanic Curriculum Union for Ocean Universities of China (hereinafter referred to as the Union). Use the regional union mechanism, gather the advantages of members and construct the excellent courses as well as select the outstanding teachers to promote the sharing of excellent resources and the course teaching reform, improve the wisdom education system, providing service for students of ocean universities and social students to choose and learn the curriculums. The Union selects high quality curriculums. Learners can finish all the learning tasks and get the certificate of qualification through PC, Pad and mobile phones. Moreover, the Union recombines the teaching process, enlarges the teaching effects and expanding the scope of audiences, which greatly reduce the cost of acquiring high quality marine educational resources and lay a solid foundation for the oceanic education in "dealing with more affairs with less cost" and promote the popularization and balance development of oceanic education. Besides, the Union actively explores the innovative teaching patterns like online learning and blending instruction to meet students' personalized learning needs, improve the curriculum quality and promote the innovation of oceanic teaching patterns.

\section{CONCLUSION}

The ocean universities as the main force of oceanic education shoulder the responsibility to improve people's marine consciousness and help students to establish the ocean idea and spread the knowledge about ocean culture. Oceanic general education curriculum is an important way to spread the knowledge about ocean culture to students as well as an important sign to manifest the characteristics of ocean universities. It is necessary to construct the blue oceanic general education curriculum and train students into the talents with the blue and open consciousness of ocean conservancy and sustainable development at the same time attract more excellent talents to join in the ocean development and train more talents with high quality for the national marine cause. 


\section{REFERENCES}

[1] Oceanic Education in Australia and Its Enlightenment, Cui Ailin, Zhao Qinghua, Heibei Academic Journal, 2008/02

[2] Defects of the Oceanic Education of Our Country in Marine Talent Training and Countermeasures, Wang Qi, Wang Xuan, Science and Management, 2011/03

[3] Researches on the Development of Oceanic Education and the Marine Talent Training in Our Country, Pan Aizhen, Miao Zhenqing, Journal of Zhejiang Ocean University (Humanities Science Edition), 2009/02

[4] Develop the Oceanic Education and Marine Science and Technology and Promote the Marine Economic Development of Zhejiang, Wu Zhongping, Zheng Caier, Ocean Development and Management, 2009/05. 